Revista Iberoamericana, Vo1. LXXXI, Núm. 250, Enero-Marzo 2015, 53-71

\title{
BANQUETES, HAMBRUNAS Y LIBERTAD EN LA CUBA DEL SIGLO XIX
}

\author{
POR \\ Armando ChÁvez Rivera \\ University of Houston, Victoria
}

\begin{abstract}
"Vista de una casa de calderas", un grabado del francés Frédéric Mialhe, hace confluir a esclavos, servidumbre doméstica y amos en el mismo recinto de un ingenio azucarero donde el jugo de la caña se espesa en medio de calores infernales. ${ }^{1}$ En ese escenario, dos damas de cutis sonrosado y vestidos de lazos y volantes beben una infusión mientras un sirviente sostiene el servicio de porcelana. A un costado, uno de los esclavos revuelve una masa en proceso de convertirse en diferentes clases de azúcar. El grabado de Mialhe es una síntesis compacta de la Cuba colonial, como si pretendiera mostrar el entramado de esclavitud y vasallaje, producción y consumo, carencia y abundancia. En ese entorno, los esclavos de rostro borroso valen por la fuerza de sus brazos, mientras los burgueses se refinan y particularizan. Los recipientes de cobre donde se cuaja el zumo movido por siluetas negras de gesto adusto tienen como contraparte la porcelana que reposa lánguidamente en manos de las hacendadas. Bajo el mismo techo coinciden hervores de calderas y jugos degustados delicadamente. Al fondo, el vapor difumina el cielo tropical y los penachos de las palmeras. ${ }^{2}$ El supuesto edén caribeño queda eclipsado y se resume en un primer plano de brutalidad y lujos.

De igual modo, en la literatura hispanoamericana pueden encontrarse excelentes pasajes en que la prodigalidad o la carencia de alimentos revelan la emergencia, consolidación o desaparición de grupos sociales. El lazarillo de ciegos caminantes (1773), de Alonso Carrió de la Vandera, menciona a gauchos o gauderios como sujetos subversivos cuya proliferación se debe a la abundancia de comida. La feracidad del terreno y la profusión de animales fueron condiciones propicias para su aparición en Uruguay y Argentina: “A las orillas del río Quarto hay hombre que no teniendo con que comprar unas polainas y calzones mata todos los días una vaca o un novillo” (207).
\end{abstract}

1 El francés Pierre Toussaint Frédéric Mialhe (1818-1881) es considerado iniciador del costumbrismo gráfico en Cuba.

2 Cecilia Valdés, de Cirilo Villaverde, describe también una visita de los hacendados a una casa de calderas. Allí, la familia de Cándido Gamboa degusta guarapo con gotas de ron. 
Los gauchos sacrificaban reses y las consumían cerca de Montevideo, llenándose de un vigor que Carrió de la Vandera veía como amenaza y condición propicia para la desidia: "Estos colonos, o por mejor decir gauderios, no tienen otra providencia que la de un trozo grande de carne baxo de su ramada" (210). Una situación parecida ocurre en Cuba, donde la profusión de frutas, viandas y cerdos jíbaros en los montes fue el sustento de transgresores, fugitivos y cimarrones. La disponibilidad de comida se convierte así en dato valioso para la caracterización literaria de grupos sociales.

Las alusiones al consumo de alimentos y la estratificación social se vuelven mucho más agudas en El matadero (1839-1840, publicado en 1871), de Esteban Echeverría. El relato denuncia las limitaciones de consumo de carne impuestas con motivo de la cuaresma a la población en Buenos Aires, pero paradójicamente resultan desacatadas por miembros del clero y el poder político: “ ¡Cosa extraña que haya estómagos privilegiados y estómagos sujetos a leyes inviolables y que la iglesia tenga la llave de todos los estómagos!" (96), subraya el narrador. Las restricciones temporales de alimentos y su transgresión por las autoridades suman detalles para perfilar el ambiente de violencia y represión bajo el gobierno de Juan Manuel de Rosas. El control político se extiende así sobre la satisfacción de necesidades más básicas en provecho de unos grupos y en detrimento de otros. La distribución de alimentos deviene evidencia de un sistema en que unos gozan de prebendas mientras otros tienen que arrojarse como arpías "prontas a devorar cuanto hallaban comestible" (94).

En el mismo sentido, ciertas imágenes de la literatura cubana se erigieron entremezclando menciones a comidas, grupos y clases sociales, así como a la excepcionalidad de la naturaleza, el suelo y las cosechas, en correlación con ideales de libertad y prosperidad. Un ejemplo clásico es "Espejo de paciencia" (1608), de Silvestre de Balboa, considerado el primer poema escrito en la isla. Los versos dejan constancia de la unión de indígenas, negros y españoles para liberar a fray Juan de las Cabezas Altamirano, entonces obispo de Cuba, quien durante su visita a Bayamo en 1604 fue secuestrado por el corsario francés Gilberto Girón. La liberación del religioso es celebrada por seres mitológicos del bosque ofreciendo guanábanas, caimitos, mameyes, piñas, tunas, aguacates, plátanos y tomates, camarones, biajacas, guabinas y jicoteas, y "mil géneros de caza" (34) junto a iguanas, patos y jutías. ${ }^{3}$ El rescate pagado por los vecinos incluyó, entre otras vituallas, cien arrobas de carne. El invasor resultó finalmente ajusticiado debido a su propia gula, que lo empujó a tierra atraído por tocinos y carne a la marinera. En esta obra parece fijarse un vaticinio literario para Cuba: todo comienza y termina con comida, como territorio a fin de cuentas descubierto durante una expedición que soñaba con las especias de Ceylán.

En Lo cubano en la poesía Cintio Vitier subraya que Balboa estrena el tema de la cornucopia frutal en la literatura de la isla.

Revista Iberoamericana, Vol. LXXXI, Núm. 250, Enero-Marzo 2015, 53-71 ISSN 0034-9631 (Impreso)

ISSN 2154-4794 (Electrónico) 
Al igual que el grabado de Mialhe, la literatura sobre la isla esclavista muestra insistentemente la posición social de individuos y grupos según su acceso restringido o ilimitado a los alimentos. De ese modo, las alusiones a la comida pueden ser interpretadas como sutiles metáforas o incisivos alegatos sobre las condiciones sociales y políticas de cada etapa. Al mismo tiempo, apuntan a particularidades del desarrollo económico, como la dependencia del monocultivo y la necesidad de importaciones para cubrir el consumo alimentario. El acceso a los alimentos se convierte en constancia de la gradual estratificación social. Mientras los esclavos enfrentaban restricciones, los hacendados disfrutaban de la buena mesa entre propios e invitados, con caprichos de la cocina francesa y suculencia de viandas criollas, acomodados en palacetes cuya piedra ornada con motivos vegetales pretendía ser espejo de las haciendas.

Varios pasajes literarios sobre la Cuba decimonónica revelan información sobre los estratos sociales y su acceso a la alimentación. Nuestro propósito es mostrar cómo se perfilan en esas páginas las diferencias de clases, se observa la relación producción y esclavismo, y se instauran mitos, estereotipos y prejuicios sobre la sociedad y la naturaleza de la isla, tanto por parte de cubanos como de viajeros. Cada uno de los textos que citaremos conlleva una perspectiva distintiva según la condición social del autor: Viaje a La Habana (1844), de Mercedes Santa Cruz y Montalvo, condesa de Merlín, es una extensa crónica sobre su regreso a La Habana después de una largo alejamiento, desde la adolescencia; Ensayo político sobre la isla de Cuba (la primera edición definitiva en francés fue publicada en 1826 y en español, en 1827), de Alejandro de Humboldt, resume el resultado de meses de exploración en la isla (de finales de 1800 a marzo de 1801, y entre abril y mayo de 1804); la autobiografía del poeta Juan Francisco Manzano, único texto de su tipo escrito en Hispanoamérica en condiciones de esclavitud (la primera edición fue en inglés en 1840 y no apareció en español hasta 1937); Cartas desde Cuba, de la novelista sueca Fredrika Bremer, compendia correspondencia enmarcada entre principios de febrero e inicios de mayo de 1851; Biografía de un cimarrón (1966), de Miguel Barnet, recoge el testimonio antropológico de Esteban Montejo, quien fuera esclavo, cimarrón y finalmente hombre libre; y "Diario de campaña", de José Martí, resume sus vivencias desde el 9 de abril hasta el 17 de mayo de 1895, dos días antes de morir a los 42 años de edad. Estas obras trazan un arco sobre la sociedad colonial desde los inicios del XIX hasta las guerras independentistas.

\section{UN PARAÍSO TERRENAL: MESAS, HACIENDAS Y GUARDARRAYAS}

María de las Mercedes Santa Cruz y Montalvo (1787-1852) regresa a La Habana en 1840 luego de haber partido aún adolescente rumbo a Europa. El texto recrea el retorno a la ciudad natal, el reencuentro con familiares y amigos, el paisaje urbano y el campestre. Las alusiones a comidas, frutas y bebidas vertebran la estampa romántica

Revista Iberoamericana, Vol. LXXXI, Núm. 250, Enero-Marzo 2015, 53-71 ISSN 0034-9631 (Impreso)

ISSN 2154-4794 (Electrónico) 
e idílica de una nación joven, próspera y pacífica. Halla una nación avanzando en su maduración, en la cual se hacen visibles caracteres distintivos de un modo de ser criollo a diferencia de los extranjeros y especialmente de los españoles. Algunas claves para la comprensión de ese nuevo mundo, que la condesa se empeña en describir vehemente en cartas enviadas a sus íntimos en Europa, son la feracidad de las tierras y el clima propicio. Desde esa perspectiva, la isla es a la vez campo frutal y jardín, con alimentos tan deliciosos que son casi indescriptibles. Encuentra un país donde todo parece apoyarse en lo natural, franco y suave, incluso en la espontaneidad de las relaciones sociales y el modo de las mujeres de envejecer sin afeites.

La mesa bien servida se torna epicentro de la familia. La abundancia de alimentos compartidos cohesiona a los parientes y contribuye a una mayor integración con la servidumbre. Cada banquete será expresión del poderío económico, pero también sello de identidad personal, calidad de la vida familiar y magnitud de la autoridad patriarcal. La opulencia de la familia se expresa en la construcción de palacetes coloniales en que las galerías del patio central devienen holgados comedores donde se alivia el calor y se dispone de suficiente espacio para numerosos comensales. Las viviendas se reacomodan para un mejor disfrute de los agasajos entre parientes e invitados. Almuerzos y cenas "tienen siempre un cierto aire de fiesta que las dan el número de convidados y de criados y la desordenada profusión de los manjares" (14). La condesa se asombra de que en esos convites se gasten "tres o cuatro mil duros" (34) para garantizar un menú pródigo, aunque concurran unos pocos. ${ }^{4}$ En La Habana, puente entre Europa y las antiguas colonias, se sirve lo mejor de la cocina metropolitana y de la propia. "No hay casa opulenta que no tenga un cocinero francés, y no pueda reunir de este modo en su mesa los platos más exquisitos de la cocina francesa, con las riquezas de este género que la naturaleza prodiga a nuestras colonias" (14). A través de la alegoría de una mesa rica y variada se reafirma la condición híbrida, combinación de lo mejor de Europa y del Nuevo Mundo. En la narradora no aflora nostalgia por lo dejado en París y, en cambio, pone el elogio frutal y culinario en función de prestigiar a sus antepasados y el lugar de nacimiento. Reafirma así un linaje previo a su partida a Europa y su matrimonio con un conde bonapartista.

En Viaje a La Habana, lo cubano autóctono es elevado a un plano similar o superior a lo europeo, pero incluso resulta tan exquisito que no puede ser apreciado plenamente por quien no haya viajado o nacido en esas latitudes. No basta entonces con escribir en francés ni valiéndose de referentes compartidos con los europeos para transportarlos imaginariamente a las exquisiteces cubanas. La visitante saborea caimitos, zapotillos y mameyes. No puede referir plenamente lo que siente al probar esas frutas. Esta realidad intensa le lleva a la misma postura de Cristóbal Colón y de los cronistas de Indias

4 La suma resulta fabulosa si se tiene en cuenta que con 45 ó 50 duros se garantizaba la manutención de un esclavo durante todo un año, según estimados de Humboldt (179).

Revista Iberoamericana, Vol. LXXXI, Núm. 250, Enero-Marzo 2015, 53-71 ISSN 0034-9631 (Impreso) 
cuando quedaban sin palabras para describir los nuevos territorios que ofrecían a la corona española. Es un mundo que colapsa las nociones establecidas. En el pináculo de la cultura, el lector europeo se ve súbitamente impedido de comprender y gozar esa otra dimensión natural. La condición europea se convierte en limitación ante la gama de asombros que la condesa describe como suyos e intrasmisibles:

Yo misma que no las pruebo hace muchos años, no sabré decirte con qué delicia saboreo estos camitos que parecen terciopelo, estas zapatillas suaves y de un gusto silvestre, estos mameys, alimento de las almas bienaventuradas en los valles del otro mundo, según la creencia de los habitantes de Haiti, y en fin el mamon, crema esquisita, cuyo gusto compuesto de los mas deliciosos perfumes es un néctar digno del Paraiso (14). ${ }^{5}$

En pleno siglo xix la isla se reafirma como espacio que todavía guarda sorpresas y secretos insondables. Bremer es mucho más efectiva en su correspondencia al describir formas, sabores y texturas. Sus descripciones siempre remiten a referentes compartidos con los interlocutores europeos: "La plantación de café que yo visité estaba totalmente en flor. Parecía como si hubiese caído una nevada sobre los arbustos verdes" (114). Los mameyes de Santo Domingo le recuerdan grandes manzanas de color gris pardo, los zapotes de color marrón semejan naranjas pequeñas, los mangos parecen almendras gigantescas entre un follaje parecido al de "nuestros castaños" (40), las güiras son grandes como cabezas colgadas de árboles de tamaño análogo a los manzanos y los bananos lucen como palmeras de porte humano. Su exploración trata de ser tan objetiva que hasta dibuja plantas e insectos encontrados a su paso.

En contraste, las descripciones de Viaje a La Habana se tornan subjetivas. Se trata de una riqueza tan seductora que la visitante la asume como propia y superior aunque no pueda explicarla del todo:

No podeis figuraros el efecto de esta metamorfosis mágica, de estos perfumes embriagodores que exhalan las frutas mezcladas con el aroma de las flores. Tiene algo de refinado y estan muy en armonía con la vida sensual de este pais [...] (66)

Afectuosamente, la condesa les echa en cara una limitación a sus interlocutores y parece atribuirla a que están en Europa y no comparten la identidad híbrida de ella. La expresión augura una nostalgia futura y tiene ya el sesgo de lo que pronto será pérdida, como el "aquel olor delicioso de flores y miel" (327) que Humboldt evoca a su regreso a Europa, o "aquellas hicoteas de Masabo, Q Que no las tengo y siempre las alabo" (33), del poema de Balboa. El elogio se agiganta cuando anticipa la futura sensación de carencia.

Las frutas de la isla se convierten en motivo de obsequio, acompañadas de flores, dulces y monedas. Lo natural perecedero se eleva a la par de dijes y onzas de oro. El

5 Las citas corresponden a la edición príncipe de Viaje a La Habana reproducida en la edición crítica de Adriana Méndez Rodena (2008). Se mantiene la ortografía original.

Revista Iberoamericana, Vol. LXXXI, Núm. 250, Enero-Marzo 2015, 53-71 ISSN 0034-9631 (Impreso)

ISSN 2154-4794 (Electrónico) 
lujo y la civilización de Europa encuentran contraparte en jardines y frondas caribeñas. La opulencia de los hacendados compite con la exuberancia natural. Es tal la riqueza del campo que no parece existir otra forma de vivir que no sea en el exceso: se es rico como una consecuencia natural. Cualquier lujo patrimonial puede ser interpretado como lógica derivación de la apoteósica vegetación. Posiblemente las páginas de Humboldt hayan servido de fermento imaginativo a Merlín. Ambos reflejan una isla que vale como una joya. Lo que Mercedes de Santa Cruz hace ver a los europeos a modo de sublimación estética, Humboldt ya lo había descrito en términos económicos. El aristócrata alemán saca cuentas precisas al afirmar que la isla exporta "por medios lícitos e ilícitos" (222) en azúcar, café, tabaco, cera y cueros un monto que "menos una tercera parte, es lo mismo que Méjico ha suministrado en la época de la mayor prosperidad de sus minas" (222). Los productos de la isla se ponderan como si fueran metales preciosos. Humboldt recuerda que:

algunos escritores españoles han comparado muchas veces la isla de Cuba, por la riqueza de sus producciones agrícolas, con las minas de Guanajuato en el Méjico; porque efectivamente Guanajuato, a principios del siglo XIX, ha suministrado una cuarta parte de toda la plata mejicana y una sexta de toda la Americana. (175)

Cuba ya no es ensalzada en términos de tesoros posibles como en las cartas de Colón, sino por las tangibles utilidades de sus exportaciones de azúcar, café, cera y miel. Los cañaverales isleños se transfiguran así en imaginarios yacimientos de plata.

La condesa de Merlín describe una isla que se autoabastece. Pendiente de las noticias del exterior en cuanto a la moda, la literatura, la ópera y las disposiciones metropolitanas, Cuba se goza y ufana de sus comidas y frutas, desplazando la cocina foránea. Los platos criollos comparten la mesa con los europeos, pero la predilección crece ante los primeros. "Los señores de la alta clase, a pesar del lujo europeo de sus mesas, reservan la verdadera simpatía para el plato criollo" (34). La visitante le aclaró a su familia que no había viajado para que le sirvieran manjares franceses, sino para volver a saborear los criollos y en especial el ajiaco. Descrita en esos términos, la isla parece girar en torno a sí misma, al menos en cuanto a placeres culinarios, y es capaz de reinventar lo que no tiene. Al describir las frutas, Bremer dice que los mangos son conocidos como "las manzanas de Cuba" (40), mientras que la papa es felizmente sustituida por la sabrosa, exquisita y "noble raíz de la yuca" (187). Al sentarse a la mesa, los criollos pueden olvidarse del mundo.

La condesa penetra los hábitos alimentarios de los cubanos, sus gustos y la relación entre la alimentación y el clima. El arroz se impone junto a las legumbres y las frutas, mientras las carnes resultan pesadas para los calores tropicales. El clima parece condicionar la inclinación por comidas más ligeras. Compara a los habaneros con pájaros que comen poco y a cualquier hora del día, picando frutas o terrones de azúcar. La alegoría

Revista Iberoamericana, Vol. LXXXI, Núm. 250, Enero-Marzo 2015, 53-71 
sobre los capitalinos toma peso: tan suaves y ágiles como los describe, semejan aves más que humanos. "Son sobrios más bien que gastrónomos" (34), concluye. No queda constancia de que conozca otra mesa que no sea la de los potentados criollos. La condesa no menciona las importaciones de vinos, carnes y cereales provenientes de Europa y los Estados Unidos. No comparte el almuerzo de una campesina, no se aloja en posadas ni visita barracones de esclavos o chozas de libertos como sí lo hace Bremer. Merlín no sabe qué comen a diario los esclavos. Tal como plantea el crítico peruano Julio Ortega en El discurso de la abundancia al analizar varios textos fundacionales de la literatura hispanoamericana, "la abundancia y la carencia se interpolan, contrastivamente, como dos modos de ver y de interpretar, de representar y evaluar" (13) la realidad del Nuevo Mundo. Por tanto, la sublimación esteticista y hedonista de la condesa al referirse a la prodigalidad de los hacendados, soslaya las carencias sufridas por los esclavizados.

Bremer es efectiva al resumir la relación entre esclavismo, producción y consumo cuando describe a su hermana el proceso de obtención del azúcar en una plantación y remata el relato: "Y esta es la historia de la caña de azúcar antes de que llegue a tu taza de café. ¡Ay! ¡Que esta dulzura se extraiga bajo tal amargura, y que los goces de los hombres cuesten tantos sufrimientos humanos! (93). La imagen de la infusión endulzada con trabajo esclavo y servida en taza señorial remite al grabado de Mialhe. Si Merlín borra el sufrimiento del esclavo, Bremer y Humboldt lo denuncian: "La ley no limita ni el castigo del esclavo ni el tiempo de trabajo, ni prescribe tampoco la cantidad ni la calidad de los alimentos" (80), sostiene Humboldt y recuerda con nota al pie que "una cédula real del 31 de mayo de 1789 había intentado arreglar el alimento y el vestido, pero nunca se ha observado" (280). Humboldt expone claramente la correlación entre producción y progreso en su nexo con el esclavismo.

El clima tropical benigno descrito por la condesa se transmite al panorama social de la isla, dejando entrever relaciones armónicas entre amos y vasallos. Desde esa perspectiva, la convivencia transcurre apaciblemente entre la tolerancia y la colaboración. La narradora toma como referencia a su propio tío, propietario de una dotación de ochocientos esclavos. El esclavista es descrito como patriarca ejemplar que comparte conocimientos, bienestar y comida: "Sumamente instruido en fisiología y en medicina, cura un gran número de enfermedades, y no se limita a sus hijos y esclavos" (15), mientras su esposa "envía parte de las viandas delicadas de su mesa a sus esclavos viejos y enfermos" (15). En ese edén de abundancia repartida aparentemente existe un sentido humanista que impulsa a cooperar y proveer. La repartición de comida reafirma el presunto ambiente de liberalidad a pesar del esclavismo: "excepto a la hora de la comida, se encuentra a sus negras tendidas todo el día en el suelo sobre esteras de junco, cantando, conversando y peinándose unas a otras" (15). La narración difiere de las páginas de Cecilia Valdés, en que la acaudalada señora Rosa Gamboa es mezquina con su servidumbre, implacable en los escarmientos e indiferente a los sufrimientos.

Revista Iberoamericana, Vol. LXXXI, Núm.250, Enero-Marzo 2015, 53-71 ISSN 0034-9631 (Impreso)

ISSN 2154-4794 (Electrónico) 
Bremer hace más objetivo su relato descubriendo las diferencias de consumo entre las casonas y los barracones. La sueca coteja los dos mundos coexistentes en haciendas donde sobrevuela el miedo a las rebeliones:

veíamos los fuegos rojos que brillaban, allá en el trapiche del señor Chartrain, y oíamos los cantos salvajes y los gritos que de allí procedían. Allí estaba la vida sin descanso del trabajo esclavo, la fuerza del látigo, el horno ardiendo de la esclavitud; aquí, la libertad, la paz y el descanso bajo el bello cielo de los trópicos, en el seno de este rico jardín de frutas. (88)

La plantación colonial y esclavista ciñe a la primigenia y arcádica Cuba de flores $\mathrm{y}$ frutos. Bremer se desplaza por los campos sin poderse sustraer de esos contrastes.

La repartición generosa de alimentos por parte de los amos refuerza la imagen de un nexo "nutricio" con sus subalternos, pero éste a su vez se corporiza en la figura de la nodriza. El mismo pecho succionado por amos y esclavos tiende vínculos, colocando a las amas de leche y sus amamantados en posición de supuestos parientes:

Llegan en seguida mi hermano de leche, un negro alto, de mas de seis pies, hermoso como su madre, de dulce y tierna fisonomía. En fin, ¿lo creerás? hasta mamá Agueda, la nodriza de mi madre, que vive aun, ha andado dos leguas, á pesar de sus muchos años, para venir á besarme la mano, y llamarme su hija... (13)

Tal parece que la leche estableciera un vínculo equiparable al sanguíneo. Una imagen muy diferente brinda Cecilia Valdés, en que las relaciones interraciales motivan tensiones y por tanto la nodriza resulta expulsada de la casa señorial habanera al ingenio de provincia. María de Regla conoce los secretos de la familia: sus senos han saciado a la hija del matrimonio Gamboa y a la ilegítima de Don Cándido. En la novela de Villaverde, amamantar deviene intimidad satanizada entre blancos, esclavos y mestizos -casi preámbulo del incesto-; sin embargo, resulta acto de entrañable cercanía en la crónica de Merlín.

Tres textos tan diferentes como los de Humboldt, Merlín y Bremer, en cuanto a constitución, lenguaje y perspectiva ideológica, concuerdan en reflejar mesas bien provistas. El asombro de Humboldt es mayor cuando se refiere a las importaciones de bebidas de Europa y cereales de los Estados Unidos. "Estos vinos, licores y harinas, de un valor de 3.300.000 duros, se consumen únicamente por las clases acomodadas de la nación" (235). La mesa de los criollos pudientes se refinaba y diversificaba. "En medio de la prosperidad y de la civilización siempre en aumento de la Habana, no hay que lastimarse del desarrollo de un lujo enteramente europeo" (235), sostiene. La opulencia culinaria no es autosuficiente como la describe Merlín, sino que tiene nexos con Europa y los Estados Unidos como parte de un incremento general de las importaciones. "Se

Revista Iberoamericana, Vol. LXXXI, Núm. 250, Enero-Marzo 2015, 53-71 ISSN 0034-9631 (Impreso) 
maravilla uno al ver cuán considerable es ya el consumo interior de un país que sólo cuenta 325.000 blancos y 130.000 de color" (233), afirma Humboldt refiriéndose a tejidos de hilo, algodón y seda llevados desde Europa, así como muebles, hierro, acero, madera, quincalla y hasta jabón de Castilla. Sin embargo, el estereotipo de paraíso frutal resulta engañoso si las constantes de feracidad y profusión se suponen extendidas al resto de la agricultura. Flores y frutos abundan, pero no ocurre necesariamente lo mismo con algunos productos agrícolas, el pescado y la carne:

Tal es la composición de aquellas sociedades que habitan el terreno más fértil que la naturaleza puede ofrecer para el mantenimiento del hombres, tal la dirección de los trabajos agrícolas y de la industria en las Antillas, que, en el clima afortunado de la región equinoccial, la población carecería de subsistencias si no fuera por la actividad y la libertad del comercio exterior. (234)

Humboldt describe una economía dañada por el monocultivo y que hace al país dependiente de la exportación de alimentos para completar las raciones destinadas a los esclavos y las necesidades de otros sectores de la población. Detalla entonces las importaciones de arroz, legumbres secas y carnes saladas (235). Humboldt observa una agricultura sometida a propósitos europeos, los cuales dañan tanto "el orden de la naturaleza" (236) como los verdaderos intereses locales.

Merlín, Bremer y Humboldt reiteran la imagen de exuberancia promisoria para el desarrollo social. La primera insiste en exaltar una feracidad que permite la vida sensual y despreocupada. Al evaluar la cantidad de posibles habitantes indígenas, Humboldt afirma que "Cuba rodeada de costas abundantes en pescados y cuyo suelo es tan inmensamente fértil podría haber mantenido muchos millones de aquellos Indios” (128). En su camino a Trinidad, en la zona central de la isla, encuentra evidencias de buena tierra esperando la mano del hombre para dar cosechas abundantes. La condesa afirma que la tierra "no necesita aquí de un cultivo esmerado, ni de abono. Para producir muchas cosechas al año bastan algunos días de arado, y esparcir sobre ella unos cuantos puñados de granos" (35). Tal profusión y poco esfuerzo sustentan la estampa de campesinos abandonados al amor y el placer:

Confiado en la prodigalidad de una naturaleza espléndida, y seguro de hallar en todas partes mieses y frutas en gran abundancia, la pereza, la voluptuosidad y el amor de la independencia se apoderan de su alma, y ponen un sello en todas las acciones de su vida. (36)

La sensualidad del guajiro resulta natural en ese entorno de germinaciones, floraciones y crecimientos vegetales. De modo general, Merlín, Bremer y Humboldt coinciden en su visión hechizada de los campos. En opinión de Merlín, el paraíso podría ser

Revista Iberoamericana, Vol. LXXXI, Núm. 250, Enero-Marzo 2015, 53-71 ISSN 0034-9631 (Impreso)

ISSN 2154-4794 (Electrónico) 
colocado en San Marcos, mientras que a Humboldt le parece que "la bóveda estrellada del firmamento bajaba sobre la sabana o pradera" (337) una noche en que contempla yerbas, ramas y hojas cubiertas de insectos fosforescentes con tintineos rojizos cuando se desplaza desde Trinidad hasta un embarcadero de la costa sur en "un hermoso coche guarnecido con damasco viejo carmesí" (331). Confluyen estos narradores en perfilar un cuadro real maravilloso del país.

La descripción embelesada de los visitantes europeos se llena de naturaleza comestible. No olvida Humboldt que en las noches sopla un viento que lleva desde la tierra hasta las naves "aquel olor delicioso de flores y de miel que es característico de los surgideros de la isla de Cuba" (327). El énfasis en "aquel" parece remitirlo a una reminiscencia grata conservada solamente por él o unos pocos elegidos. Por su parte, la condesa se libra de los mosquitos "dándome baños de aguardiente de caña, que aquí son una panacea universal aplicable a todos los males, y haciéndome abanicar después sin enjuagarme por una negra mientras estoy escribiendo" (18). Los alcoholes de la isla se convierten en antídoto natural contra las plagas. Un mismo líquido es panacea embriagadora para la mente y alivio para el cuerpo.

El conocimiento de la sociedad se vuelca más allá de lo propiamente proveído por la naturaleza; los viajeros y cubanos describen la identidad local y de cada grupo especificando la forma en que preparan sus comidas. Con una mirada atenta en la situación social de la mujer, su vida y limitaciones en el recogimiento de mansiones y haciendas, Bremer camina por La Habana y se pregunta "dónde están los fogones y qué hacen con el humo" (27) que no empaña el aire transparente. A lo largo de su testimonio abunda en muchos otros datos culinarios que permiten imaginar el escenario doméstico de hacendados, campesinos y esclavos, también el grado de sofisticación de las costumbres, y las similitudes o diferencias con los enclaves metropolitanos. Asimismo, brinda detalles sobre la preparación de los manjares, su procedencia, sabores y texturas. En la mesa señorial su mirada se inclina hacia el plato más humilde:

La mesa de la señora Carrera es también una de las más exquisitas. Pero ninguno de los platos selectos me ha agradado más que el favorito de los negros esclavos, el "fufú", una especie de pudding duro, pero muy gustoso, que ellos hacen con bananos o plátanos aplastados y que comen con una salsa de tomates y otras verduras. (187)

Su curiosidad de exploradora incluye la degustación sin remilgos. Llega a la bahía de La Habana y no espera a descender de la nave para probar, encantada, los grandes "racimos de plátanos dorados" (19) y trozos de caña recién subidos a bordo. Merlín y Bremer cultivan curiosidades diferentes. Si la primera es hedonista, la segunda revela una búsqueda organizada e in crescendo al punto de que se lanza a visitar jardines particulares para "apreciar mejor flores y frutos" (194) y tiene un encuentro con el célebre naturalista Felipe Poey (1799-1891), quien le obsequia ejemplares de mariposas.

Por si la confluencia de platos europeos y tropicales no fuera suficiente para retratar un espacio paradisiaco, la condesa de Merlín aporta la descripción de una capital en que

Revista Iberoamericana, Vol. LXXXI, Núm. 250, Enero-Marzo 2015, 53-71 
las formas del renacimiento se combinan pétreamente con frutos antillanos y penachos de piñas en "guirnaldas y flores esculpidas" (51). Es un mundo que se goza a sí mismo y reproduce lo propio como prueba de orgullosa identidad. "La alianza del antiguo y del Nuevo Mundo vive aquí en la piedra (...)” (51). Sin embargo, de acuerdo con la descripción, lo viejo impuesto en la piedra es superado ampliamente por la naturaleza alrededor, sobre todo en las haciendas. Son campos, jardines y estancias ideales para ubicar el paraíso por la confluencia de naturaleza y cultura: "si se fuera a buscar en la tierra un lugar para el Paraíso, le colocaría en el valle de San Marcos. Allí se encuentran reunidas bajo el más hermoso cielo del mundo las bellezas sublimes de la naturaleza, y las bellezas estudiadas del arte" (72). En el valle confluyen cocoteros, árboles del pan, algodoneros, vainilla, tamarindos y cerezos. Las flores se entrecruzan con los frutos como si el paisaje se tornara comestible. Comer es un acto estético en que las flores son apreciadas como frutas, y viceversa. La condesa estimula el apetito de sus amigos europeos. Cuba es un compendio del occidente y del oriente, pero a la vez una entidad diferente en la medida que es un paraíso.

La Cuba futura imaginada por Humboldt, una vez superado el esclavismo, sería de habitantes mejor instruidos que transformarían la economía rural y dejarían de producir en función de los bajos precios fijados por Europa, aunque sin abandonar el cultivo del azúcar y el café “como basa principal de la existencia nacional” (235). En ese hipotético futuro, Cuba quedaría liberada del control colonial sobre sus cultivos. Entonces, con "una población agrícola, libre e inteligente, sucederá progresivamente a la población esclava, sin previsión ni industria" (237). Humboldt avizora un país con una prosperidad impulsada y compartida por el campo, pero a la vez con el aporte de otros sectores.

El alemán subraya la dependencia del monocultivo y del engranaje esclavista concentrado en pocas manos mientras Merlín rehúye insistir en las implicaciones de la esclavitud. Humboldt y Bremer ofrecen una visión más balanceada sobre la realidad cubana y de la disponibilidad de alimentos por parte de las diversas clases sociales. El paraíso terrenal descrito en Viaje a La Habana fija como premisa la existencia de frutos y alimentos a los cuales tienen acceso los diferentes grupos, en una abundancia que les permite armonía y plenitud. Las confrontaciones clasistas y étnicas son borradas por la condesa porque supuestamente hay espacio para la prosperidad colectiva en un una isla tan gloriosa que semeja un pedazo de paraíso desprendido sobre las llanuras.

\section{HAMBRUNAS Y CASTIGOS}

Otros dos protagonistas de la literatura cubana se movían por La Habana en la década del treinta: el poeta esclavo Juan Francisco Manzano (1797-1853) y el novelista Anselmo Suárez y Romero (1818-1878), autor de la novela Francisco: El ingenio o las delicias del campo, que circuló en La Habana en versión manuscrita desde 1839 y

Revista Iberoamericana, Vol. LXXXI, Núm. 250, Enero-Marzo 2015, 53-71 ISSN 0034-9631 (Impreso)

ISSN 2154-4794 (Electrónico) 
tuvo su primera edición en 1880. El primero fue un esclavo doméstico posteriormente manumitido y el segundo, hijo de una familia venida a menos a pesar de poseer un ingenio azucarero. Para los dos, la comida se vuelve una obsesión. Ambos pasan hambre y sus testimonios difieren de la estampa de opulencia consagrada por Merlín.

Suárez y Romero describe en Francisco que en las fincas el rato "concedido a los negros para comer y descansar al mediodía es tan corto, que no les basta apenas para asar su ración de tasajo, sino que a medio cocer y a veces caminando hacia el campo tienen que engullírsela de carrera" (83). El acto de comer carece de placer y se limita a satisfacer una necesidad. En "Mi vida como preceptor”, Suárez y Romero relata su pesadilla para disponer de alimentos en la época que recibía un magro salario por brindar instrucción primaria. ${ }^{6}$ Durante más de un año comió una vez al día. "Una sola taza de café, un solo vaso de refresco, una sola fruta, un solo carruaje de alquiler, nada de esto ni de otras muchas cosas pude disfrutar en los catorce meses" (ctd en Carrera Saquí 28), confiesa. El joven escritor se describe "hallándome siempre con hambre" (ctd en Carrera Saquí 29) justo cuando la condesa de Merlín visita La Habana y describe una holgura que parece encimarse ineludiblemente sobre todos los cubanos.

El centenar de páginas de la autobiografía de Manzano rememora los latigazos, las extenuantes labores al servicio de una familia aristocrática y la agonía del inestable acceso a la comida. A Manzano se le encierra sin agua ni alimentos cada vez que sus propietarios consideran que debe ser castigado. ${ }^{7}$ La comida se le convirtió en tal obsesión que le generó fama de glotón. Comía excesivamente cuando había circunstancias propicias, pero a continuación sufría indigestiones y quebrantos de salud. El esclavo vivía consciente de que el acceso a los alimentos era intermitente y formaba parte de una caprichosa estrategia de escarmientos de su segunda propietaria. En una ocasión fue castigado a varias sesiones de latigazos por la sospecha de que había robado y comido un capón. Poco después se descubre que uno de los mayordomos de la casa había sido el culpable.

La crítica de Manzano contra el esclavismo subraya su situación de siervo sin adecuada nutrición, lo cual le impide cumplir efectivamente con sus labores. El joven se tiene que nutrir de residuos lanzados caprichosamente por sus amos. En el piso, recibe las sobras. A su vez, se ve compelido a comer en el mismo lapso de sus propietarios. Sólo

${ }^{6}$ Consultar fragmentos de "Mi vida como preceptor" citados en el prefacio "Vida, pasión y gloria de Anselmo Suárez y Romero", de Mario Carrera Saquí.

7 Fernando Ortiz describe que entre las formas de castigo en las Antillas estuvo la máscara, un aditamento que "se aplicaba sobre la cara y se sujetaba con un candado cerrado con llave. Con la cabeza metida en tal artefacto, el esclavo no podía comer ni beber sin permiso" (159). El castigo era aplicado a los borrachos, a los que ingerían tierra y hasta a los que comían caña (159). En las haciendas visitadas por Bremer, los esclavos comían trozos de caña sin que fueran castigados. Sin embargo, la visitante aclara que no llegó a ver lo peor que ocurría en las plantaciones.

Revista Iberoamericana, Vol. LXXXI, Núm. 250, Enero-Marzo 2015, 53-71 ISSN 0034-9631 (Impreso) 
puede ingerir alimentos mientras lo haga su ama. El súbdito tiene que sincronizarse con el cuerpo dominante en la satisfacción de las necesidades más elementales. Estas escenas transcurrían a principios del siglo XIX, etapa en que, de acuerdo con Michel Foucault, se afinaban mecanismos de control biológico sobre individuos y colectividades; o sea, todo lo relacionado con estrategias de alimentación, desarrollo, reproducción, salud y rendimiento en función de la productividad. Si nos atenemos al encuadre teórico de Foucault, resumido en su concepto de biopolítica, ganan trascendencia las referencias de la literatura antiesclavista al control de la alimentación de los esclavos, tanto para reprimirlos en el interior doméstico como para potenciar su rendimiento agrícola.

Si la queja emancipadora de Manzano apunta hacia las penurias de su alimentación, también se refiere a la comida cuando rememora el mejor período de su vida. Establece una correspondencia de corte positivo entre la disponibilidad de alimentos y una dichosa etapa de la infancia. Hasta los seis años, Manzano gozó de la protección de la marquesa Beatriz de Jústiz. Al describir esa época, que terminó con el fallecimiento de la dama, el poeta se evoca como un miembro más de la familia y tan consentido como los vástagos blancos. Su madre era la criada de confianza de la marquesa, pero también había sido encargada de amamantar a un hijo de la familia. El futuro marqués se nutría del mismo pecho que alimentó a Manzano. Tal vez por ese motivo, el niño mulato se haya creído durante la infancia semejante a los aristócratas. El pecho de la madre vuelve a ser un vínculo conciliador que acercaba a esclavos y esclavistas. Manzano intenta reafirmar imaginariamente ese nexo al subrayar también que fue bautizado con el mismo faldellín de una de las nobles. Haber succionado la misma leche y que su cuerpo fuese contenido entre las telas cosidas para un cuerpo hegemónico, como orgullosamente rememora, suponen pruebas de pertenencia a un tronco familiar; es un intento de tender puentes físicos y emocionales, tal como una nodriza negra llama "mi hija" a la condesa de Merlín. Consumir la misma leche crea entre estos individuos un espejismo de hermandad. Sin embargo, si las nodrizas que amamantan a los amos se convierten en figuras usualmente reverenciadas; en cambio, las que alimentan a los esclavos, hasta los seis o siete años de edad antes de ser mandados a trabajar o puestos en subasta, cargan sobre sí el grotesco de los barracones; se les llama "cebadoras" (32), recuerda Montejo en Biografía de un cimarrón. Manzano no aborda ese punto; su introspección se vuelca al ámbito doméstico soslayando los barracones y a los esclavos de las plantaciones. Para Manzano, la adolescencia será un reconocimiento de su condición subordinada o, para decirlo de modo mucho más simbólico, la toma de conciencia de la exclusión de la mesa familiar a la cual creyó pertenecer. El resultado es un cuerpo debilitado, sin fuerzas, incapaz de cumplir con tareas cotidianas, casi incapaz de ser esclavo. ${ }^{8}$

El ingenio, de Manuel Moreno Fraginals, aborda la imposibilidad de los esclavos de satisfacer necesidades tan básicas como dormir. Se les permitía cuatro horas de sueño y, excepcionalmente, seis (166).

Revista Iberoamericana, Vol. LXXXI, Núm. 250, Enero-Marzo 2015, 53-71 ISSN 0034-9631 (Impreso)

ISSN 2154-4794 (Electrónico) 
Finalmente Manzano logró la manumisión gracias a una colecta organizada por el crítico y editor Domingo del Monte. Luego sufrió otros infortunios cuando constató que su liberación no implicaba una inserción plena en la sociedad colonial, revela su primer biógrafo, Francisco Calcagno, en Poetas de color (1869). De igual modo, al protagonista mestizo de $S a b$ tampoco le basta ganar la lotería para considerarse en igualdad de condiciones con los individuos blancos. Una vez liberado, Manzano sobrevivió gracias a sus múltiples oficios, en especial el de repostero. Una carta de del Monte revela que éste preparaba deliciosas tajadas de sidra, y que luego de ser manumitido puso "un tren de dulcería" y sus postres estaban de moda en La Habana. ${ }^{9}$ Alguna vez del Monte le había solicitado sus servicios de cocinero. Manzano no tenía derecho a un asiento en la mesa señorial de la nación, sólo podía acceder a la condición periférica de proveer deleites y sabores a la élite de su época.

\section{EL MONTE Y LA MIEL DE LOS PALENQUES}

Biografía de un cimarrón ilumina otras perspectivas muy diferentes a las de Humboldt, Merlín y Bremer. Merlín y Manzano se mueven en los aburguesados interiores domésticos, Bremer viaja por ciudades y campos, se sienta en todas las mesas y visita todas las cocinas. Esteban Montejo conoce el barracón y el monte. Su retorno a la naturaleza es un viaje en sentido contrario al de la plantación. Su testimonio sobre la isla y la búsqueda de alimentos implica una lucha con ese espacio natural que la condesa describe como ya dominado y al servicio de azucareros y guajiros: jardines, guardarrayas con palmeras, desbordantes cosechas, frutas y flores, y un telón de fondo de ocio y fiestas. Para Merlín, las siembras de los campesinos se dan sin esfuerzo. Nada dice de los rigores de los cortes de caña. Para Bremer, las plantaciones son las grandes heridas del país. Para Montejo, el monte es territorio de sobrevivencia en que el hombre caza pero también puede ser presa. El fugitivo teme ser engullido por un majá (serpiente) o apresado por perros de rancheadores. La subsistencia constituye un forcejeo con el medio ambiente que, sin embargo, tiene las bondades de la feracidad. La condición silvestre, de terreno intrincado y no dominado por el sistema de explotación, permite al esclavo la existencia al margen de la sociedad. Los pasajes de Montejo cazando y procurándose los alimentos en los montes de Cuba sugieren un retorno a lo natural precolombino o a las espesuras africanas. Para Merlín, la Cuba arcádica son palacios y haciendas; para Montejo, el monte y los palenques; para Manzano, el pecho de su madre.

El espacio silvestre se convierte en territorio de libertad donde los cimarrones caminan hacia el este creyendo que llegarán a su continente de origen (Humboldt 277). En los palenques, los cimarrones cultivaban al estilo africano (Franco 65) y se instaura

9 Carta de del Monte citada por Roberto Friol en Suite para Juan Francisco Manzano (168-169).

Revista Iberoamericana, Vol. LXXXI, Núm. 250, Enero-Marzo 2015, 53-71 ISSN 0034-9631 (Impreso) 
un nuevo orden que concede espacio incluso a blancos fugitivos. La obtención de alimentos es central en este régimen, permitiendo el canje y la adquisición de armas de fuego, pólvora, machetes, sombreros, ropa e instrumentos de trabajo (Franco 106). Se comercia con mayorales y "elementos blancos de dudosa reputación que vivían aislados en los campos" (72). Franco describe un sistema de contrabando que hacía fluir cera y miel desde los palenques hasta las fincas campesinas. El monte de la barbarie expande así su libertad subversiva midiendo fuerza con la ciudad y la plantación, e inmiscuyendo a campesinos, mayorales, esclavos, piratas y corsarios. La producción de alimentos se convierte en un boquete económico y político por permitir la presencia de fugitivos y su avituallamiento. Se subsistía al margen de la sociedad colonial, pero no sólo en Cuba. Documentos de 1577 detallan que una tropa española abatió a corsarios y negros libertos que compartían "una merienda campestre" (Franco 25) en costas caribeñas de Panamá. De acuerdo con ese pasaje, la comida aunaba en la sobrevivencia, el disfrute y el comercio a los sujetos más subversivos de la época. Llegamos aquí a un punto clave para comprender la Cuba colonial y esclavista: se trata de la intersección de la comida con los castigos, pero también de la comida con la libertad. Los alimentos generados en la clandestinidad de los palenques abrieron márgenes para una libertad que se expandió más allá de los cimarrones y fue de provecho hasta para los mambises.

Cecilia Valdés, Cartas de Cuba y Biografía de un cimarrón, entre otras obras, dejan constancia de esclavos que adquieren cierta independencia o compran su libertad brindando servicios como cocineros, productores agrícolas y vendedores de alimentos ya elaborados, como también se observa en grabados de Tipos y costumbres de la Isla de Cuba, del bilbaíno Víctor Patricio Landaluze. Un ejemplo explícito del nexo entre comida y libertad personal es la sobrevivencia de parejas homosexuales gracias a los conucos. Montejo apunta: "Eran buenos trabajadores y se ocupaban de sembrar conucos. Les daban los frutos a sus maridos para que los vendieran a los guajiros" (34). La independencia de las relaciones homosexuales encuentra asidero económico en la producción individual de alimentos. A su vez, Montejo recuerda que los esclavos criaban cerdos para venderlos a bajo precio a los campesinos o canjear la carne por leche. "Los conucos fue lo que salvó a muchos esclavos. Lo que les dio verdadera alimentación" (20), rememora. En general, el cultivo en los conucos incluía viandas y legumbres, muchas de las cuales han quedado incorporadas a los platos ofrecidos a las deidades del panteón afrocubano. Consecuentemente, resulta llamativa la profusión de cocoteros y bananos contemplados por Bremer cerca de chozas de esclavos y libertos, frutos posiblemente destinados también a las ofrendas. ${ }^{10}$

10 Mitos y leyendas de la comida afrocubana, de Natalia Bolívar Aróstegui y Carmen González, resume amplia información sobre frutos, bebidas y comidas presentes en los cultos afrocubanos.

Revista Iberoamericana, Vol. LXXXI, Núm. 250, Enero-Marzo 2015, 53-71 ISSN 0034-9631 (Impreso)

ISSN 2154-4794 (Electrónico) 
MARTÍ Y LOS TRIBUTOS GUAJIROS

Pese a las muchas contingencias del regreso a Cuba en 1895, Martí fue dejando en su diario constancia de desayunos, almuerzos y comidas. El retorno se convierte en un encuentro deslumbrado con la cocina local: arroz, frijoles y huevo frito; puerco guisado con plátanos y malangas, tasajo de vaca, caldo de plátano, salchichón, jutía asada en parrilla; miel en panal, café endulzado con guarapo, chocolate, ron de pomarrosa; pan, casabe y galletas; frangollo, dulce de plátano y queso, raspa de coco con miel. Son tributos guajiros para la comitiva de liberación; provienen de la mesa campesina. Ya no se trata del homenaje de las deidades del bosque, como en el poema de Balboa, sino de los propios criollos.

Martí toma nota de quiénes envían la comida y así irrumpe la gente más sencilla en las páginas de la literatura y la historia por regalar sus gallinas o haber ayudado a preparar un guiso: "a mediodía vienen los hermanos de Luis, orgullosos de la comida casera que nos traen: huevos fritos, puerco frito y una gran torta de paz de maíz" (497). La escena se repite en este documento de pocos folios: "De una casa nos mandan café y luego gallina con arroz" (495). Más adelante agrega: "De la casita pobre envían de regalo una gallina" (503). Desfilan vecinos empeñados en calmar el hambre y la sed de la tropa: "Viene Abraham Leyva, con Silvestre cargado de carne de puerco, de cañas, buniatos, del pollo que manda La Niña" (488). El campo es refugio y lugar que provee para la subsistencia: "Domitila, ágil y buena, con su pañuelo egipcio, salta al monte y trae acopio de tomate, culantro y orégano" (491). "Entra el vecino dudoso Pedro Gómez y trae de ofrenda café y una gallina" (494). La comida fluye hacia los libertadores como si se repitiera el homenaje triunfal al obispo Altamirano: "A lo alto, paramos bajo unas palmas. Viene llena de cañas la gente" (495). Han pasado casi tres siglos de la bienvenida a Altamirano y la isla está a punto de liberarse del gobierno español pero, al igual que en el poema de Balboa, la comida es la mejor ofrenda y comer es una fiesta.

Martí relata el ambiente de hermandad de la comida compartida: "uno me da un chopo de malanga. Otro, en taza caliente, guarapo y hojas" (491). Cocinar y comer les reafirman como colectivo. El general Gómez "prepara dulce de coco con miel" (492). Martí se inmiscuye en el acto de cocer los alimentos: "asamos buniatos" (488). Accede a una Cuba que no conoce: "el general me dio a beber miel para que probara que luego de tomarla se calma la sed" (491). Comer es una tarea colosal, casi milagrosa, y siempre un hallazgo cuando la comida viene de lejos, sobre hombros y en medio de la noche, venciendo distancias y peligros. Al igual que los cimarrones, la tropa se mueve entre la sobrevivencia y la inminencia de algún enfrentamiento. Se come caóticamente, lo que haya disponible. Son combinaciones dispares, dictadas más por la escasez que por la lógica de un menú: "Comimos salchichón y chocolate y una lonja de chopo asado (493). El retorno a la patria está cargado del sabor de sus comidas y la sonoridad de

Revista Iberoamericana, Vol. LXXXI, Núm. 250, Enero-Marzo 2015, 53-71 ISSN 0034-9631 (Impreso)

ISSN 2154-4794 (Electrónico) 
sus nombres. Aflora la idea de la nación como banquete, pero cercano al palenque y distante de la mesa señorial: "almorzábamos buniato y puerco asado cuando llegó Luis -ponen por tierra, en un mantel blanco, el casabe de su casa" (496). En ese momento las jerarquías se diluyen y prima el afecto.

Las descripciones de Montejo y Martí difieren de las de Merlín. Para los primeros, el acto de comer está revestido de urgencia. Sus bocados parecen más sabrosos: "A lonjas de a libra nos comemos su queso, remojado en café (...)" (527). Antes ya se han topado con el hambre: "Cojea la gente, aún no repuesta. Apenas comieron anoche" (503). Merlín describe con más asombro impresionista que con apetito. Para ella, el espectáculo de la comida y las frutas es sobre todo visual y esteticista; se le va la vista tras la voluptuosidad frutal que reafirma una riqueza natural extensible a los bienes patrimoniales. Bremer comprende la condición social de cada habitante mirando lo que sirve en su mesa; el conocimiento de cada grupo pasa por contemplar y probar sus comidas: "He engordado y he rejuvenecido aquí" (139), afirma al término de sus casi tres meses de estancia. Humboldt sopesa las mesas señoriales con curiosidad de economista. En el comer, Martí contempla un instante colectivo de humanidad. En sus descripciones se siente el fragor de la cocina: desuellan y salan una jutía, sacrifican gallinas, asan viandas, adoban carnes con zumo de limón y corren mieles e infusiones que aplacan la sed. "Y nos pusimos a la miel ansiosos. Rica miel, en panal" (490). Martí come agradecido, emocionado y hambriento. Su diario es un eco de cada alimento. Al escribir ha revivido el goce de lo digerido.

"Espejo de paciencia", Viaje a La Habana, Cartas desde Cuba y el "Diario de campaña" trazan un panorama que va desde el nacimiento de la isla a las letras hasta el albor de la independencia. Si las deidades del bosque cubano reciben al obispo Altamirano liberado del invasor extranjero y a sus salvadores ofrendándole los mejores frutos del monte, de igual modo la población criolla acoge a Martí y Gómez. Trofeos, tributos y bienvenidas están aliados a lo comestible. Una campesina, Caridad Pérez y Piñó, citada por el apóstol en su diario, da la bienvenida a su rancho y ofrece café endulzado con miel: "Pasen sin pena, aquí no tienen que tener pena" (493). Bremer se interna sola en un poblado de negros libertos cercano a Limonar, occidente de Cuba. Curiosa llega hasta una puerta y el anciano desconocido le recibe con un saludo de una sola e incitante palabra: “¿Café?” (85). Ubicadas cronológicamente, estas obras dan cuenta de momentos específicos de la literatura y la historia. En la mirada de paisanos y viajeros, la caracterización del cubano aúna comidas y bebidas con homenajes y ceremoniales.

En el poema de Balboa todavía hay un regusto ajeno, de exotismo, en una isla virginal de indígenas, náyades y centauros, en que se topan un esclavo etíope, un obispo español y un corsario francés. En la obra de Merlín, el criollo ya tiene su propia identidad y la naturaleza ha sido puesta al servicio del sistema esclavista, de opulencia llevada al derroche y deseosa de embelesar a Europa. Desde la mesa criolla, Europa

Revista Iberoamericana, Vol. LXXXI, Núm. 250, Enero-Marzo 2015, 53-71 ISSN 0034-9631 (Impreso)

ISSN 2154-4794 (Electrónico) 
se difumina y queda mucho más lejos de las costas cubanas. En Viaje a La Habana, la isla es un territorio colonial en que los rasgos nacionales y criollos se van acentuando, pero todavía es una pintura edénica que soslaya las tensiones del esclavismo, las cuales Humboldt, Manzano, Suárez y Romero, Bremer y Montejo ofrecen consternados. En el diario de Martí, las ofrendas de los guajiros confirman el reconocimiento de un liderazgo emancipador y el repudio contra el poder colonial. No son deidades, sino hombres y mujeres criollos; no se trata del ajiaco compitiendo con la cocina francesa, sino de platos con sonoridad cubana, tampoco se honra a un miembro de la jerarquía católica vinculado al poder metropolitano, sino a quienes se avizoran como primeras figuras de la república. Al final del diario se mezclan la comida y el afecto filial: "Asan plátanos y majan tasajo de vaca, con una piedra en el pilón para los recienvenidos [...] y me trae Valentín un jarro hervido en dulces con hojas de higo" (533). Son las últimas palabras del diario. Martí muere unas horas después.

La literatura cubana del siglo xix puede ser leída como crónica de las potencialidades de la isla y el proceso de estratificación social a través de sus detalles sobre la riqueza natural, la agricultura, la cocina local, y los nexos entre esclavitud, colonialismo y monocultivo. Comida y literatura confluyen en perfilar estampas memorables de la nación. Más de un siglo después, la literatura y el arte cubanos se siguen valiendo de alusiones a la comida para apuntar a descalabros económicos y políticos. En especial, las referencias al racionamiento y la hambruna tienen una sugestiva conexión con el imaginario de un país que se constituyó bajo el ideal de paraíso frutal, pero cuyos grupos de poder han utilizado la distribución de alimentos en función del control y la represión. Desde 1492, la comida ha sido en Cuba sinónimo de identidad, esplendor y originalidad, pero también de sufrimientos y castigos.

\section{OBRAS CITADAS}

Balboa, Silvestre de. "Espejo de paciencia". Espejo de paciencia; El príncipe jardinero y fingido Cloridano; Testamento de D. Jacinto Joséf Pita. La Habana: Letras Cubanas, 2008. 19-53.

Barnet, Miguel. Biografía de un cimarrón. La Habana: Letras Cubanas, 1993.

Bolívar Aróstegui, Natalia y Carmen González. Mitos y leyendas de la comida afrocubana.

San Juan, PR: Plaza Mayor, 2000.

Bremer, Fredrika. Cartas desde Cuba. La Habana: Arte y Literatura, 1981.

Calcagno, Francisco. Poetas de color. La Habana: Imprenta Mercantil, 1887.

Carrera Saquí, Mario. Prefacio. "Vida, pasión y gloria de Anselmo Suárez y Romero".

Francisco: El ingenio o las delicias del campo. La Habana: Arte y Literatura, 1974. 25-46.

Carrió de la Vandera, Alonso. El lazarillo de ciegos caminantes. Madrid: Editora Nacional, 1980.

Revista Iberoamericana, Vol. LXXXI, Núm. 250, Enero-Marzo 2015, 53-71 ISSN 0034-9631 (Impreso) 
Castellanos, Jorge e Isabel Castellanos. Cultura afrocubana. Vol. 1. Miami: Universal, 1988.

Echeverría, Esteban. La cautiva. El matadero. Madrid: Cátedra, 1986.

Foucault, Michel. Vigilar y castigar. México: Siglo XXI, 1994.

Franco, José Luciano. Los palenques de los negros cimarrones. La Habana: Departamento de Orientación Revolucionaria del Comité Central del Partido Comunista de Cuba, 1973.

Friol, Robert. Suite para Juan Francisco Manzano. La Habana: Arte y Literatura, 1977.

Humboldt, Alejandro de. Ensayo político sobre la isla de Cuba. París: Jules Renouard, 1827.

Landaluze, Víctor Patricio. Tipos y costumbres de la Isla de Cuba. La Habana: Taveira, 1881.

Manzano, Juan Francisco. Autobiografía del esclavo poeta y otros escritos. William Luis, ed. Madrid: Iberoamericana, 2007.

Martí, José. “Apéndice. Diario de José Martí (Abril 9 a mayo 17 de 1895)”. Diario de campaña. La Habana: Instituto del Libro, 1968. 485-533.

Mialhe, Pierre T. Frédéric. Álbum pintoresco de la isla de Cuba. Berlín: B. May y Ca, 1860.

Moreno Fraginals, Manuel. El ingenio: el complejo económico cubano del azúcar. La Habana: Comisión Nacional Cubana de la UNESCO, 1964.

Ortega, Julio. El discurso de la abundancia. Caracas: Monte Ávila, 1990.

Ortiz, Fernando. Los negros esclavos. La Habana: Ciencias Sociales, 1996.

Pérez de la Riva, Juan. El barracón y otros ensayos. La Habana: Ciencias Sociales, 1975.

Santa Cruz y Montalvo, María de las Mercedes de (Condesa de Merlín). Viaje a La Habana. Adriana Méndez Rodena, ed. Doral, FL: Stockcero, 2008.

Suárez y Romero, Anselmo. Francisco: El ingenio o las delicias del campo. La Habana: Arte y Literatura, 1974.

Villaverde, Cirilo. Cecilia Valdés. Caracas: Ayacucho, 1981.

Vitier, Cintio. Lo cubano en la poesía. La Habana: Instituto del Libro, 1970.

Revista Iberoamericana, Vol. LXXXI, Núm. 250, Enero-Marzo 2015, 53-71 
